\title{
CONTEMPORARY CHALLENGES TO BULGARIAN PROFESSIONAL EDUCATION AND TRAINING
}

\author{
T. Atanassova-Kalaydzieva ${ }^{1^{*}}$, R. Rempfer ${ }^{2}$ \\ ${ }^{1}$ Department of Management, Trakia University, Stara Zagora, Bulgaria \\ ${ }^{2}$ Management Consulting,VDI, Germany
}

\begin{abstract}
In the sphere of human development the contemporary professional education and the educational institutions play a major part. Education fulfils a social function as it is a method of socialization of the individual in the society and at the same time increases society's culture. A more important role professional education plays in the growth of economy and the standard of living of a nation. Its new way of thinking lifelong learning to develop its intelectual potential as a prerequisite for a more successful career on the labour market. The aim of this article is to discover the challenges to the professional education in Bulgaria, to point out the problems and propose measures to its increase its efficiency. To reach these aims an analysis of the Bulgaria professional education based on statistics, own research and reports of other authors should be worked out.
\end{abstract}

Key words: professional education, training, challenges, opportunities.

\section{INTRODUCTION}

Education plays a social function. It is a means for the individual's socialization in society and a way to increase their culture. Professional training plays an ever increasing role. Its mission is to educate the individual during their whole life and to provide opportunities for the development of their intellectual potential as a precondition for a more successful career in the labour market.

The professional training of the human capital of each country must correspond to the needs of the national economy. The realization of the professional training must comply with the circumstances facing the national economy. In the short run these circumstances are related to the social and economic consequences of the economic crisis, while in the long run they reflect the demographic processes and globalization.

The aim of the study is to show the condition of the Bulgarian professional training and to identify some of the main problems, preventing the fulfillment of the priorities put forward in the Europe 2020 Strategy and the

${ }^{*}$ Correspondence to: Todorka Atanassova Kalaydzieva, Department of Management, Trakia University, Stara Zagora, Bulgaria, tel: +359 42699 415,E-mail: tatanassova@abv.bg
National Development Programme: Bulgaria 2020.

The analysis of the Bulgarian system for professional training was made on the basis of the information provided by the official statistics, our own researches and studies of other authors.

\section{CHALlENGES TO BULGARIAN PROFESSIONAL TRAINING AND EDUCATION}

The headline priorities in the Europe 2020 Strategy put forward highly ambitious and difficult to attain targets:

- $75 \%$ of the people aged $20-64$ should be employed, the percentage for Bulgaria being higher $-76 \%$;

- the problem with the dropouts and early school leavers should be solved. For the EU the percentage of dropouts and early school leavers should be reduced from $15 \%$ to $10 \%$, the percentage for Bulgaria being $11 \%$;

- the share of people aged 30 - 34 having completed higher or equivalent to it education should be increased from $31 \%$ to $40 \%$ till 2020, while for Bulgaria the percentage should reach at least $36 \%$.[4]

Priority 1 of the National Development Programme: Bulgaria 2020 is improving the access to and enhancing the quality of 
ATANASSOVA-KALAYDZIEVA T., et al.

education and training and the qualitative characteristics of the work force. For its fulfillment two sub priorities have been set: 1.1. Providing accessible and qualitative education for the development of the individuals through the modernization of the educational system and ensuring its adaptability to the needs of the labour market; 1.2. Improving of the qualitative characteristics of the work force. [4]

The development of the professional education and training faces increased world competition, population aging which is very notable in Bulgaria, technological innovations and the policies set for the social inclusion in Europe. [5]

The graduates of secondary professional schools are potential applicants for admission to higher schools and universities and their professional training influence the quality of higher education.

With the objective of ensuring a better professional realization in keeping with the European challenges, Bulgaria should, in a short-term programme, apply the necessary solutions for finding a balance between the supply and demand of workforce with a certain qualification (high school or university) at the labour market. [4]

\section{CONDITION OF THE PROFESSIONAL EDUCATION AND TRAINING IN BULGARIA}

\subsection{Regulatory framework}

The regulatory framework, governing the professional education and training in the Republic of Bulgaria comprises the provisions of several laws:

- Public Education Act, which regulates the national structure, functions and management of the system of national education;

- Level of Education, General Education Minimum and Curriculum Act, which regulates the conditions and the procedure for completing one level of education and passing to the next level; [3]

- Vocational Education and Training Act (promulgated in 1999 with 24 amendments), which plays an important role for the development of the system of professional education and training. Pursuant to its provisions the purpose of the professional education and training is to prepare the citizens for successful realization in the national economy by creating conditions for acquiring professional qualification and its continuous improvement; [2]
- Employment Promotion Act, which regulates the public relations in adults' vocational guidance and training;

- The Professional Qualifications Recognition Act- adopted in Bulgaria because of the EU requirements;

-Labour Code, regulating the social partnership, the collective labour agreement and the individual employment agreement, through which the activities of the professional education and training could receive broad public support and optimal implementation in business enterprises.

\subsection{Educational institutions in the system of} professional education and training in Bulgaria Educational institutions are those, directly conducting training to students in organized classes (groups) at educational institutions or through distance learning. As of the present moment the educational institutions in the system of professional education and training are several types: Vocational schools, Vocational Secondary Schools, Art Schools, Sports Schools, Vocational Colleges and Centers for Vocational Training, Vocational Guidance and Qualification. [2]

For the 2013/2014 school year the number of schools conducting training for professions included in the List of professions for professional education and training in Bulgaria is $488[8,10]$ :

- $82,3 \%$ are vocational secondary schools, which amounts to 401 schools;

$-4,9 \%$ are sports schools - 24 schools for the whole country;

- 4,7\% are art schools- 23 schools;

$-8 \%$ are vocational colleges in the country which enroll students who have completed their secondary education. Their number is 39. They conduct professional training for professions with a fourth degree of professional qualification included in the List of professions for professional education and training;

$-11,9 \%$ are private schools- 58 schools.

It can be seen that from 2000/2001 school year to the present moment the percentage of Art school has increased with $14,3 \%$. The number of Vocational Colleges has increased with $54 \%$. The opposite tendency is found in the professional secondary schools which have decreased with $15,6 \%$ for the same period.

The changes in the structure of the school network for the last fifteen years come as a result of the socioeconomic and demographic processes in different regions of the country. The demographic situation shows alarming 
ATANASSOVA-KALAYDZIEVA T., et al.

tendencies about the inclusion of young people in the labour market in Bulgaria, where the youth unemployment rate for people aged $15-24$ is $26,8 \%$ (National Statistical Institute,third quarter of 2013), which amounts to almost 65 thousand people.

\subsection{Students in the system of professional education and training in Bulgaria}

Boys prevail in vocational training, their percentage being $60 \%$ as compared to girls who are $40 \%$. The total number of students studying in vocational institutions for the 2013/2014 school year, according to the data of the National Statistical Institute, is 140882 . [8,10] $73,1 \%$ of them study for professions with III degree of professional qualification; $23,3 \%$ study for professions with II professional degree, while 2,3\% study for professions with I professional degree. In comparison, in 2000/2001 school year the total number of students studying in vocational institutions was higher - $186135 ; 74,6 \%$ studied for professions with III degree of professional qualification; $24 \%$ studied for professions with II professional degree and $1,4 \%$ studied for professions with I degree. 27,4 thousand pupils (2013) graduated from the Arts and Sports Schools.

Vocational training is conducted in 58 private vocational schools, in which for 2013/2014 school year studied 2493 pupils, constituting $1,8 \%$ of the total number.[8]

It was found that for a period of thirteenfourteen years the number of students in the vocational schools was reduced with almost 46000 students, the number amounting to $25 \%$. That can be explained with the effect of the socioeconomic development and the permanently established tendency of negative population growth in the country.

The tendencies pointed above are also influenced by the manner of financing the vocational schools and the vocational secondary schools in Bulgaria. For the 2013/2014 school year vocational education and training was financed as follows $-55,3 \%$ of he funds came from the Ministry of Education and Science, 17,1\% from the Ministry of Agriculture and Food, and 27,6\% came from mixed municipal-private financing. The mixed municipal-private financing receives funds from the Ministry of Culture and the Ministry of Youth and Sport depending on the professional profile of the educational institution. The main source of financing of the vocational training in
Bulgaria is still the state with its ministries and municipalities while the share of private financial funds, received by big companies, branch organizations, foundations, etc, is comparatively small.

\subsection{Centers for professional training in Bulgaria}

They are educational institutions for professional training, which carry out professional training and award professional qualification to persons aged 16 and over. The training offers opportunities for acquiring, updating and improving of vocational knowledge and skills in a profession, or a part of it, with I, II and III degree of professional qualification.

The number of the centers for professional qualification in the country is constantly rising. At the end of 2013 there were 908 centers for professional qualification in Bulgaria. Only for a year their number increased with 21 centers $(2,4 \%)$ as compared to 2012. In 2013 100,5 thousand people were trained in the centers for professional qualification. $51 \%$ of them studied for updating of their knowledge and skills; $29 \%$ of them studied for acquiring a degree of professional qualification; 5\% wanted to acquire professional qualification for different professions and $15 \%$ - completed other types of training.[8] For the unemployed, and especially for the people with unequal social opportunities, the vocational training in a center for professional qualification is the only opportunity to find a job. For those, having a job, the professional training is a chance to keep it.

At the moment the most popular are the qualification courses, which are financed under EU programmes (European Social Fund) and are cofinanced by the state budget with the aim of employment encouragement $87 \%$. Only $2 \%$ of the training in the centers for professional qualification is financed by national programmes, while $11 \%$ percent of the training uses other financial sources. 10]

\subsection{Degrees of professional qualification in Bulgaria}

Pursuant to the provisions of the Vocational Education and Training Act there are four degrees of acquired professional qualification in Bulgaria [2]:

- $\quad I^{\text {st }}$ degree (corresponding to the qualification of unskilled worker) - It is awarded to people having completed VI grade or the initial stage of primary education, as 
well as to those who have completed a literacy course at the age of 16 under the provisions of the Employment Encouragement Act, or under programmes and projects, financed by the Structural Funds of the EU. In 2013 first professional degree in the vocational schools and classes admitting pupils after competed VI, VII and VIII grade, was awarded to only 549 pupils, the number being considerably smaller as compared to previous years.

$\mathrm{II}^{\text {nd }}$ degree (corresponding to the qualification of worker) - It is awarded to people having completed $\mathrm{X}$ or XI grade who are entitled to taking their state final exams for completing secondary education. Two educational spheres - Technical studies and Technical professions (28\%) and Public Services (22\%) play a leading role in the training for acquiring a second professional degree.

- $\quad \underline{\text { III }}{ }^{\text {rd }}$ degree - for people having completed secondary education (XII- grade vocational high school)after passing their state final exams. That secondary education qualification degree is acquired by people who have fulfilled the state educational standards and have received the right to practice a specific profession. The pupils studying Technical Science and Technical Professions $(30,3 \%)$, and those studying Economic Science and Administration (18\%) have the highest percentage in the process of acquiring a third degree of professional qualification;

In 2013 second and third degrees of professional qualification were awarded to 6,7 thousand and 15,4 thousand pupils respectively.

$\underline{I V}^{\text {th }}$ degree - qualification for a profession included in the List of Professions in compliance with the National Qualifications Framework for people who have completed their secondary education and are aged 16 and over (for them a previous training of at least two years is required) Vocational colleges are the educational institutions conducting that type of training. For 2013/2014 school year they were 39 , the number exceeding with $53,9 \%$ the number of colleges in 2000. 1153 people acquired fourth degree of professional qualification during the same school year.

\section{MAIN PROBLEMS FACING THE PROFESSIONAL EDUCATION AND TRAINING IN BULGARIA}

\subsection{Grade retention}

Grade retention is one of the problems continuously accompanying the process of education and training in the country. Grade retention is a strongly demotivating factor for the pupils and is the main reason for discontinuation of education. The national statistics shows that the number of pupils repeating the same grade in 2012 was about 6 thousand, which is considerably lower as compared to a ten-year earlier period when their number exceeded 16 thousand. Unfortunately this fact is not an optimistic one, but just the opposite. The structure of pupils repeating the same grade has been changed during the years. While in 2000 the numbers of retention pupils in primary and elementary education were almost equal, in 2012 the main part of retention students were in the lower secondary stage (V-VIII grades). The process can be explained with the amendments made in the Public Education Act in 2010, forbidding grade retention for pupils in grades I-III. As a result of these amendments the net coefficient for enrollment of students for the 2013/2014 school year, measured by the National Statistical Institute, for students from the primary educational stage (I-IV grades) is higher- $95,5 \%$, while for the students in the lower secondary educational stage (V-VIII grades) was much lower - 79,7\%.[5,8]

\subsection{Early school leaving}

According to the definition of the European Union from 28.06.2011 early school leavers are those people aged 18-24 who have completed elementary, or a lower stage of formal education, and are no longer engaged in any kind of further education and training. [6]

From 2005 to 2013 the percentage of dropouts was reduced with about $8 \%$, i.e. from $20,4 \%$ to $12,5 \%$ (the percentage for the EU being 12). The national target is the reduction of that percentage to $11 \%$ till 2020 as compared to the $10 \%$ for the EU. [5]

The European statistics shows that for the last five years the number of early school leavers in most countries has been reduced. The number of dropouts is the highest in Turkey, Spain, Malta, Portugal and Romania, while in Croatia, Slovenia, Switzerland, the Czech Republic and Poland their percentage are the lowest. The percentage of dropouts in Bulgaria is near the average value for the European Union. According to the national statistics the main reasons for early school leaving include family problems, pupils' leaving the country to live abroad and pupils' unwillingness to go to school. (Figure 1) 

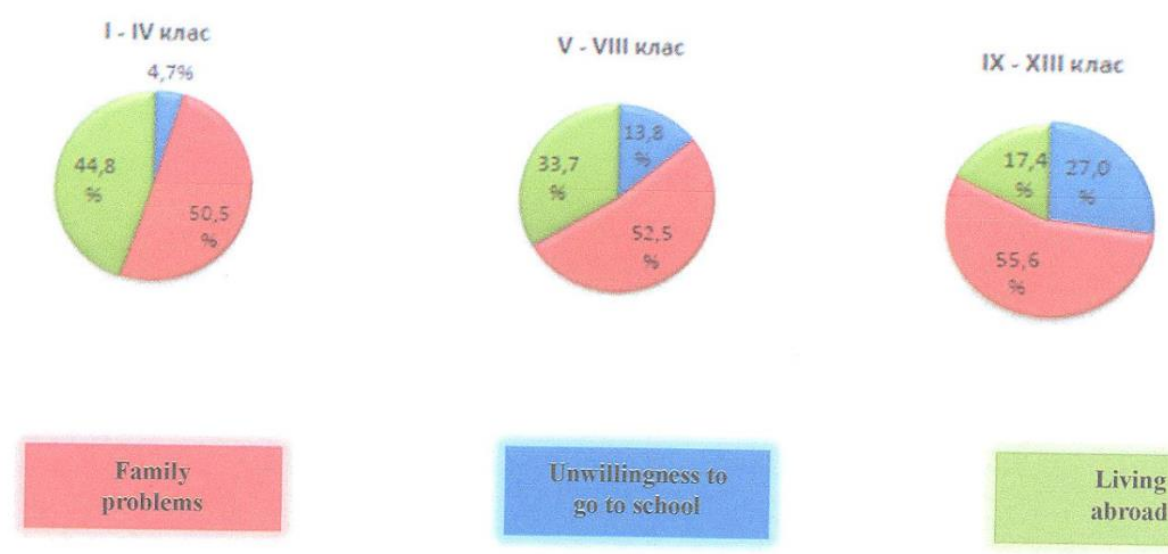

Living

abroad

Figure 1.: Reasons for early school leaving in Bulgaria [5]

There are considerable differences in the number of early school levers in the different regions of the country. The lowest percentage of early school leavers - only 4,8\% (2013) is measured in the Southwestern region, which is characterized by the most rapid economic development in Bulgaria. It is the only region in which the percentage of early school leavers is lower than the average ratio in Bulgaria. On the other hand, the Northwestern region is economically the least developed and the early school leavers there are almost four times as much-18,2\% (2013).

\subsection{Reduction of the number of teachers and} aging of teachers in the system of professional education and training in Bulgaria

The number of teachers in the vocational schools and colleges during the 2013/2014 school year was 12598 , the number being considerably lower as compared to the 2000/2001 school year when the number was 18009 , i.e there was a $30 \%$ reduction.[10]

The other main problem is the aging of teachers. In 2000/2001 school year 23\% of the teachers in the vocational schools and colleges in Bulgaria were under the age of $34,50,7 \%$ were aged $35-50$, and $26,3 \%$ were aged 60 and above. In 2013/2014 school year the percentage of teachers under the age of 34 was only $9 \%$, while the percentage of those aged 35 -50 was $42,1 \%$. There is a considerable rise in the percentage of teachers aged 60 and over $49 \%$. At the same time the number of young people who want to work as teachers is constantly decreasing. That fact can be explained with a variety of reasons - low salaries, low prestige of the teaching profession, bad working conditions, etc.

\subsection{Quality of vocational training}

The most serious problem found in a study of PISA is that the quality of Bulgarian education, professional education and training included, is not improving despite the measures taken.[5] In 2008 a system of delegated school budgets was adopted for all schools in the country with the aim of providing financial independence and more funds for the process of education. Five years later the negative effects of the system became obvious. The delegated budgets force the schools to enroll and keep more and more students without putting the necessary emphasis on the quality of training. The school governing bodies try to enroll more pupils so that they can receive a bigger delegated budget. That led to the acceptance of pupils with lower grades in the so called elite schools. On the other hand, whole classes and/or whole vocational school, which taught pupils for acquiring important for the country professions with a second degree of professional qualification had to be closed down. The results of the system adopted in our country show that there exists no correlation between the educational costs and expenditure and its quality. [5]

\section{DIRECTIONS FOR INCREASING THE QUALITY OF PROFESSIONAL EDUCATION AND TRAINING IN BULGARIA}

The quality of professional education and training is a crucial factor in the process of reaching the targets put forward in Europe 2020 Strategy and the National Development Programme: Bulgaria 2020. The main efforts of the country for the current programme period must be directed towards overcoming of the problems in the system of vocational 
ATANASSOVA-KALAYDZIEVA T., et al.

training and increasing of its quality. Some of the main measures in that area could be defined as follows:

The number of early school leavers must be reduced and vocational education must be established as an important opportunity for young people seeking successful careers in the labour market. There is a need for legislative regulation of vocational training in real working environment for individuals aged 16. Training modules organization must be introduced in the process of vocational education as well as distance learning for some of the specialities taught.

The prestige and status of the professional education and training must be improved through modernization of the standards for educational content and the curricula in compliance with the contemporary requirements. Thus a workforce with modern professional qualification shall be created and the trainees shall be interested in pursuing successful careers in the profession studied. A credit system reflecting the real results achieved in the process of training must be introduced so that the credits could be used as a basis for the transition from secondary to higher education.

A necessary condition for achieving high quality vocational training shall be the introduction of a mechanism for mandatory periodical qualification of teachers in the vocational schools and colleges. That process should be cleverly combined with the system of delegated budgets. The prestige of the teaching profession must be enhanced in society so that young and highly motivated teachers could be employed in the sphere of professional education and training.

A pedagogical exchange must be introduced between the secondary schools and the universities with identical or similar professional orientation. Prominent specialists from leading business enterprises should be engaged in the training process of pupils in vocational schools.

In response to the rapid development of the information and communication technologies a contemporary school infrastructure must be created with the aim of applying the modern technologies in the process of education.

School dormitories must be built and free transportation must be provided for the pupils living in distant settlements and for those coming from low-income families. The pupils must be granted scholarships for excellent grades and real achievements in the profession studied.

A necessary condition for enhancing the quality of Bulgarian vocational education and training is the introduction of the dual education which is widely practiced in Germany, France, Switzerland and other European countries, the dual education being a form of partnership between the vocational schools and the business enterprises. [6,7] It combines training in real working environment under the guidance of a tutor during which time the pupil is hired as an apprentice in the company. The financing of the training is done on the basis of a contract, signed by and between the educational institution and the employer, thus providing for a shared responsibility between the state and the business enterprise regarding the quality of education. The system of dual education uses flexible approaches towards the organization of the process of education which are in compliance with the characteristic profile of the business enterprise and the capabilities of the trainees. Special curricula for dual education in Bulgarian educational institutions must be drawn up and the teachers and mentors that shall be engaged with it must receive special training.The introduction of dual education in Bulgaria shall facilitate the access to vocational training to people over the age of 16 , including the early leavers and dropouts. A stable connection shall be established between the educational institutions and the business enterprises, thus creating a smooth transition between schools and enterprises and reducing youth unemployment.

For the fulfillment of these measures all financial opportunities provided for by the European Structure Fund and the Lifelong Learning Programme, as well as the Erasmus Programme, must be used cleverly.

\section{CONCLUSION}

The analysis done confirmed the thesis that vocational training in Bulgaria should be regarded as one of the leading factors for an intelligent and sustainable growth of the country and its integration within the EU. In response to the European and national targets for strategic development till 2020 we must make rapid and urgent changes in the system of vocational education and training.

Bulgarian vocational education and training focuses great public expectations for the next few years which include employment increase, reduction of the level of youth unemployment, social integration and inclusion of individuals. 
It is regarded as an opportunity - everyone can receive a chance for lifelong learning and an easier access to professional training and better qualification in keeping with the ever increasing necessities of society and the labour market.

The realization of these targets needs resources - material and human. The direction is correct and we have only to follow it. That is what Randy Gage says: "you can't be pushed to prosperity, you should keep your consciousness open for it". [1]

\section{REFERENCES}

1. Randy Gage (2012) Prosperity Consciousness. How to Harness the Power of Thought?, Anhira.,Sofia

2. Vocational Education and Training Act., State Gazette, issue 68 from 30.07.1999

3. Level of Education, General Education Minimum and Curriculum Act, State Gazette, issue 67 from 27.07.1999
ATANASSOVA-KALAYDZIEVA T., et al.

4. National Development Programme: Bulgaria 2020.

5. Review of the progress of Bulgaria under Europe 2020 Strategy - employment, education, poverty,(2014), Institute for Market Iconomics, Sofia

6. Strategy for the Development of the Vocational Education and Training in the Republic of Bulgaria for the period 20152020, (2014),Sofia

7. Katya Stoyanova (2012) Comparative analysis of the Bulgarian and European Experience in the System of Vocational Education and Training, Vocational Training Magazine, year XIV, book 1, pages $70-76$

8. Education in the Republic of Bulgaria 2014 of the NSI,Sofia.

9. Education and Training Monitor 2014; ec.europa.eu/education/monitor

10.www.nsi.bg 